Jurnal Kebijakan Pembangunan Daerah, Vol.5, No.2, Desember 2021, Hal. 138 - 150

p-ISSN: 2597-4971, e-ISSN: 2685-0079

\title{
IMPLEMENTASI PROGRAM PEMBERDAYAAN SOSIAL DALAM REHABILITASI RUMAH TIDAK LAYAK HUNI DI KOTA CILEGON
}

\author{
IMPLEMENTATION OF SOCIAL EMPOWERMENT PROGRAMS \\ THE REHABILITATION UNINHABITABLE HOMES AT CILEGON CITY
}

(disubmit 29 Oktober 2021, direvisi 12 November 2021, diterima 02 Desember 2021)

Ronald Al Kausar, Rina Yulianti dan Titi Stiawati

Universitas Sultan Ageng Tirtayasa Pascasarjana Magister Administrasi Publik

Jl. Raya Jakarta Km.4 Pakupatan Kota Serang Provinsi Banten

ronaldalkausar@gmail.com

\begin{abstract}
ABSTRAK
Pengentasan kemiskinan menjadi fokus Pemerintah Daerah Kota Cilegon sebagai upaya implementasi fungsi pemerintahan. Tingkat kemiskinan di Kota Cilegon salah satunya ditandai dengan adanya rumah tidak layak huni di Kota Cilegon. Melihat hal tersebut, pemerintah daerah melakukan upaya untuk mengatasinya. Penelitian ini membahas mengenai implementasi program pemberdayaan sosial dalam rehabilitasi rumah tidak layak huni di Kota Cilegon dengan pendekatan teori dari Hill dan Hupe meliputi aspek mengelola proses kebijakan, mengelola hubungan antar organisasi dan mengelola hubungan internal dan eksternal. Metode penelitian yang digunakan adalah metode deskriptif dengan pendekatan kualitatif. Berdasarkan hasil penelitian, pengelolaan proses kebijakan pada implementasi program pemberdayaan sosial dalam rehabilitasi rumah tidak layak huni di Kota Cilegon belum sepenuhnya berjalan dengan baik dikarenakan masih adanya rumah tidak layak huni yang belum selesai direhabilitasi. Pengelolaan hubungan antar organisasi belum bersinergi dengan baik antara perangkat daerah yang mengampu urusan rehabilitasi rumah tidak layak huni. Pengelolaan hubungan eksternal dan internal belum sepenuhnya berjalan dengan baik dikarenakan penerapan kepatuhan Standar Operasional Prosedur (SOP) yang belum sesuai terkadang teknis di lapangan menjadi salah satu acuan untuk pihak terkait dalam pelaksanaan program. Kemudian minimnya pelatihan-pelatihan dan reward kepada aparatur, sehingga kurangnya motivasi.
\end{abstract}

Kata Kunci: Implementasi, Program, Pemberdayaan Sosial, Rehabilitasi, Rumah Tidak Layak Huni

\begin{abstract}
Poverty alleviation is the focus of the Cilegon City Government as an effort to implement government functions. One of the poverty levels in Cilegon City is marked by the presence of uninhabitable houses in Cilegon City. Seeing this, the local government made efforts to overcome it. This study discusses the implementation of social empowerment programs in the rehabilitation of uninhabitable houses in Cilegon City with a theoretical approach from Hill and Hupe covering aspects of managing the policy process, managing relationships between organizations and managing internal and external relationships. The research method used is a descriptive method with a qualitative approach. Based on the results of the study, the management of the policy process in the implementation of social empowerment programs in the rehabilitation of uninhabitable houses in Cilegon City has not yet fully gone well because there are still uninhabitable houses that have not been rehabilitated. The management of inter-organizational relations has not been well synergized between the regional apparatus in charge of the rehabilitation of uninhabitable houses. The management of external and internal relations has not been fully running properly due to the implementation of compliance with Standard Operating Procedures (SOP) which is not yet appropriate, sometimes the technical field becomes one of the references for related parties in program implementation. Then the lack of training and rewards for the apparatus, resulting in a lack of motivation.
\end{abstract}

Keywords: Implementation, Programs, Social Empowerment, Rehabilitation, Uninhabitable Houses 
Jurnal Kebijakan Pembangunan Daerah, Vol.5, No.2, Desember 2021, Hal. 138 - 150

p-ISSN: 2597-4971, e-ISSN: 2685-0079

\section{PENDAHULUAN}

Desentralisasi telah melahirkan otonomi daerah yang dibagi ke dalam beberapa wilayah meliputi wilayah provinsi dan kabupaten atau kota. Penyerahan urusan pemerintahan oleh pemerintah pusat kepada daerah otonom berdasarkan asas otonomi yaitu hak, wewenang, dan kewajiban daerah otonom untuk mengatur dan mengurus sendiri urusan pemerintahan dan kepentingan masyarakat setempat dalam sistem Negara Kesatuan Republik Indonesia. Pemerintahan daerah berperan sangat penting dalam menciptakan iklim pelayanan masyarakat yang lebih maju dengan pemberdayaan dan mampu menghasilkan pembangunan daerah yang merata, luas dan bertanggung jawab. Pemerintahan daerah menjadikan pilar utama dalam pelaksanaan dan penataan kebijakan pemerintah di daerah untuk kesejahteraan masyarakat melalui pelayanan, pemberdayaan dan pembangunan.

Pemerintah Daerah Kota Cilegon merupakan pusat penyelenggaraan pemerintahan daerah di Kota Cilegon Provinsi Banten. Kota Cilegon merupakan daerah otonom yang secara yuridis dibentuk berdasarkan Undang-Undang Nomor 15 Tahun 1999 tentang Pembentukan Kotamadya Daerah Tingkat II Cilegon dan Kotamadya Daerah Tingkat II Depok. Penduduk Kota Cilegon berdasarkan Basis Data Kependudukan pada Dinas
Kependudukan dan Pencatatan Sipil Tahun 2020 adalah sebanyak 441.490 jiwa yang terdiri atas 223.875 jiwa penduduk laki-laki dan 217.615 jiwa penduduk perempuan.

Capaian kinerja makro pemerintahan daerah Kota Cilegon tahun 2021 (Tabel 1) menunjukkan bahwa pengentasan angka kemiskinan menjadi perhatian dan fokus serius Pemerintah Daerah Kota Cilegon sebagai upaya implementasi fungsi pemerintahan dalam hal pelayanan, pemberdayaan dan pembangunan kepada masyarakat. Kota Cilegon dalam menanggulangi kemiskinan belum sepenuhnya berhasil. Hal ini terlihat dari kurun waktu dua tahun tersebut jumlah dan tingkat kemiskinan Kota Cilegon mengalami kenaikan, jika dibandingkan dengan tahun sebelumnya.

Tabel 1. Capaian Kinerja Makro Pemerintahan Daerah Kota Cilegon

\begin{tabular}{|c|c|c|c|c|}
\hline \multirow[t]{2}{*}{ NO } & \multirow{2}{*}{$\begin{array}{c}\text { INDIKATOR } \\
\text { KINERJA } \\
\text { MAKRO }\end{array}$} & \multicolumn{3}{|c|}{ CAPAIAN KINERJA } \\
\hline & & 2019 & 2020 & $(\%)$ \\
\hline 1. & $\begin{array}{l}\text { Indeks } \\
\text { Pembangunan } \\
\text { Manusia }\end{array}$ & 73.01 & 73.05 & 0.04 \\
\hline 2. & $\begin{array}{l}\text { Angka } \\
\text { Kemiskinan }\end{array}$ & 3.03 & 3.69 & 0.66 \\
\hline 3. & $\begin{array}{l}\text { Angka } \\
\text { Pengangguran }\end{array}$ & 9.68 & 12.69 & 3.01 \\
\hline 4. & $\begin{array}{l}\text { Pertumbuhan } \\
\text { Ekonomi }\end{array}$ & 5.65 & 1.79 & -3.86 \\
\hline 5. & $\begin{array}{l}\text { Pendapatan } \\
\text { Perkapita }\end{array}$ & 193.48 & 211.6 & 18.15 \\
\hline 6. & $\begin{array}{l}\text { Ketimpangan } \\
\text { Pendapatan/ } \\
\text { Ratio Gini }\end{array}$ & 0.361 & 0.340 & -0.021 \\
\hline
\end{tabular}

Sumber: Badan Pusat dan Statistik Kota Cilegon, 2021. 
Jurnal Kebijakan Pembangunan Daerah, Vol.5, No.2, Desember 2021, Hal. 138 - 150 p-ISSN: 2597-4971, e-ISSN: 2685-0079

Melihat tingkat kemiskinan di Kota Cilegon yang berpengaruh terhadap pemenuhan rumah layak huni, tentu saja pemerintah daerah Kota Cilegon melakukan upaya untuk mengatasinya. Berikut tabel capaian kinerja makro Kota Cilegon Tahun 2021.

Dari keenam indikator makro di atas, angka kemiskinan merupakan fokus pembangunan pemerintah daerah di Kota Cilegon dikarenakan sebagai upaya kemampuan daerah untuk memenuhi kebutuhan dasar masyarakat. Adapun salah satu upaya yang dilakukan untuk mengatasi kemiskinan tersebut yaitu dalam kepemilikan rumah layak huni di Kota Cilegon, maka pemerintah daerah Kota Cilegon mengeluarkan suatu program yaitu Program Rehabilitasi Rumah Tidak Layak Huni (RTLH).

Program RTLH merupakan program bantuan yang ditujukan untuk masyarakat miskin dengan memberikan bantuan keuangan dalam bentuk stimulan yang bersifat swadaya dimana masyarakat dituntut untuk membangun secara swadaya berdasarkan prakarsa masyarakat atau pemerintah dengan pendekatan berbasis pemberdayaan masyarakat. Atas dasar tersebut kemudian Pemerintah Kota Cilegon mengeluarkan kebijakan melalui Peraturan Wali Kota Cilegon Nomor 30 Tahun 2016 tentang Petunjuk Pelaksanaan Rehabilitasi
Sosial Rumah Tidak Layak Huni Kota Cilegon. Kemudian setahun setelahnya, Pemerintah Pusat membuat kebijakan Peraturan Menteri Sosial Republik Indonesia Nomor 20 Tahun 2017 tentang Rehabilitasi Sosial Rumah Tidak Layak Huni dan Sarana Prasarana Lingkungan bahwasannya pemerintah daerah baik provinsi, kabupaten/kota untuk melaksanakannya secara berkala untuk menuntaskan dan menanggulangi masalah salah satunya RTLH tersebut.

Implementasi kebijakan publik merupakan satu diantara tahapan dari proses kebijakan publik (public policy process) sekaligus studi yang sangat krusial. Bersifat krusial karena bagaimanapun baiknya suatu kebijakan, kalau tidak dipersiapkan dan direncanakan secara baik dalam implementasinya, maka tujuan kebijakan tidak akan bisa diwujudkan. Implementasi dipandang secara luas mempunyai makna pelaksanaan undang-undang di mana berbagai aktor, organisasi, prosedur, dan teknik berkerja bersama-sama untuk menjalankan kebijakan dalam upaya untuk meraih tujuan-tujuan kebijakan atau program-program.

Tachjan (2006) memberikan gambaran tentang implementasi yaitu serangkaian kegiatan yang diarahkan dengan menempatkan program yang berlaku. Sejalan dengan itu lebih luas Subarsono (2015), 
Jurnal Kebijakan Pembangunan Daerah, Vol.5, No.2, Desember 2021, Hal. 138 - 150 p-ISSN: 2597-4971, e-ISSN: 2685-0079

menyampaikan bahwa kompleksitas implementasi bukan saja ditunjukkan oleh banyak aktor atau unit organisasi yang terlibat, tetapi juga dikarenakan proses implementasi dipengaruhi oleh berbagai variabel yang kompleks, baik variabel yang individual maupun variabel organisasional, dan masing-masing variabel pengaruh tersebut juga saling berinteraksi satu sama lain.

Pada hakekatnya implementasi program dilakukan dalam serangkaian kegiatan guna tercapainya suatu tujuan yang telah ditetapkan sebelumnya. Seperti yang dikemukakan oleh Jones (1994) bahwa "Implementasi merupakan rangkain kegiatan yang diarahkan untuk melaksanakan sebuah progam". Dalam bukunya yang berjudul “ $A n$ Introduction to the study of public policy (Pengantar Kebijakan Publik)" bahwa terdapat tiga hal yang menjadi pilar-pilar dalam implementasi program, yaitu organisasi, interprestasi dan aplikasi.

Hill dan Hupe (2002), menjelaskan bahwa ada tiga aspek dalam mengelola implementasi kebijakan publik yaitu mengelola proses kebijakan, mengelola hubungan antar organisasi dan mengelola hubungan internal dan eksternal.

Di Kota Cilegon permasalahan yang ditemukan, ada beberapa masalah berdasarkan temuan dilapangan dan hasil wawancara yang diolah oleh peneliti kepada aparatur Dinas Sosial Kota Cilegon yaitu belum optimalnya pengelolaan proses kebijakan oleh perangkat daerah pengampu selain Dinas Sosial Kota Cilegon salah satunya yaitu penugasan dan tanggung jawab yang jelas dalam penanggulangan RTLH di Kota Cilegon.

Belum optimalnya pengelolaan hubungan antar organisasi yaitu dikarenakan kapasitas dan kebutuhan sumber daya manusia maupun sumber daya sarana dan parasarana yang dimiliki belum memenuhi kriteria dengan jumlah kebutuhan. Hal ini dikarenakan jumlah tenaga yang ada tidak sebanding dengan wilayah yang harus ditangani begitupun dengan sarana dan prasarana yang terbatas. Belum optimalnya pengelolaan internalisasi organisasi salah satunya yaitu minimnya motivasi, pelatihanpelatihan atau bimbingan teknis khusus yang diberikan kepada para pegawai serta belum optimalnya pelaksanaan mekanisme atau penerapan Standard Operating Procedures (SOP) yang mengatur program rehabilitasi rumah tidak layak huni di Kota Cilegon. Hal ini ditandai dengan sasaran RTLH yang belum dapat diselesaikan secara keseluruhan karena keterbatasan-keterbatasan tim dan pendampingan kepada masyarakat dalam penyusunan proposal yang diajukan. Dimana, hal tentunya akan sangat berpengaruh pada pelaksanaan program 
Jurnal Kebijakan Pembangunan Daerah, Vol.5, No.2, Desember 2021, Hal. 138 - 150

p-ISSN: 2597-4971, e-ISSN: 2685-0079

rehabilitasi rumah tidak layak huni di Kota Cilegon.

Berdasarkan uraian di atas, maka peneliti tertarik untuk melakukan penelitian lebih jauh tentang implementasi program pemerintahan daerah yang berkenaan dengan pelayanan dasar urusan sosial yang berjudul tentang, "Implementasi Program Pemberdayaan Sosial Dalam Rehabilitasi Rumah Tidak Layak Huni Di Kota Cilegon”.

\section{METODE PENELITIAN}

Metode penelitian yang digunakan adalah metode deskriptif dengan pendekatan kualitatif. Oleh karena itu, teknik pengumpulan data yang digunakan oleh peneliti dalam penelitian ini yaitu dengan melakukan studi pustaka dan studi lapangan. Pertimbangan penentuan informan dalam penelitian ini didasarkan sesuai dengan informan yang bersangkutan dalam kebijakan publik dengan teknik purposive.

Teknik analisis data yang digunakan dalam penelitian ini adalah analisa deskriptif dengan pendekatan kualitatif, sehingga memerlukan strategi penyelidikan yang naturalistis dan induktif dalam mendekati suatu suasana (setting) tanpa hipotesishipotesis yang telah ditentukan sebelumnya yaitu data reduction (reduksi data), data display (penyajian data) dan conclution verification (penarikan kesimpulan) Hasan (2011). Herdiansyah (2012), keabsahan data yang digunakan dalam penelitian ini adalah menggunakan triangulasi data sumber, dimana peneliti dalam hal pengabsahan data melakukan pengecekan dan membandingkan hasil observasi, wawancara dan dokumen yang berkaitan dengan penelitian.

\section{HASIL DAN PEMBAHASAN}

Rehabilitasi sosial rumah tidak layak huni dan sarana prasarana lingkungan dimana, peran dan fungsi pemerintah sebagai pelayan masyarakat untuk membantu masyarakat khususnya penanganan fakir miskin berhak memperoleh kecukupan perumahan yang layak dan lingkungan hidup yang sehat, maka perlu diberikan bantuan sosial rumah tidak layak huni dan sarana prasarana lingkungan.

Pemenuhan rumah layak huni sebagai tempat tinggal yang aman untuk berlindung, secara mental memenuhi rasa kenyamanan dan secara sosial dapat menjaga privasi setiap orang dan keluarga. Bagi keluarga masyarakat miskin bukanlah hal yang mudah. Untuk memenuhi hak bagi keluarga masyarakat miskin di Kota Cilegon atas rumah layak huni, diperlukan rehabilitasi rumah tidak layak huni, seperti yang ditunjukkan oleh Tabel 2.

Atas hal tersebut maka, Pemerintah Kota Cilegon berupaya melakukan pelayanan kepada masyarakat sebagai pemenuhan kebutuhan masyarakat di bidang sosial 
Jurnal Kebijakan Pembangunan Daerah, Vol.5, No.2, Desember 2021, Hal. 138 - 150 p-ISSN: 2597-4971, e-ISSN: 2685-0079

Tabel 3 Aspek dalam Mengelola Implementasi Kebijakan

\begin{tabular}{|c|c|c|c|}
\hline \multicolumn{4}{|c|}{ Prescriptive Perspective Management Via } \\
\hline & $\begin{array}{l}\text { Enforcement } \\
\text { (Inputs) }\end{array}$ & $\begin{array}{l}\text { Performance } \\
\text { Management } \\
\text { Via (Outputs) }\end{array}$ & $\begin{array}{l}\text { Co- production } \\
\text { (Outcomes } \\
\text { as shared results) }\end{array}$ \\
\hline \multicolumn{4}{|c|}{ Operational Activities } \\
\hline $\begin{array}{l}\text { Managing policy } \\
\text { Processes }\end{array}$ & $\begin{array}{l}\text { Making responsibilities } \\
\text { explici }\end{array}$ & Creating 'interfaces' & Making discretion explicit \\
\hline $\begin{array}{l}\text { Managing inter- } \\
\text { organizational } \\
\text { relations }\end{array}$ & $\begin{array}{l}\text { - Creating clarity on tasks } \\
\text { and competence } \\
\text { - Taking care of sufficient } \\
\text { resources }\end{array}$ & $\begin{array}{l}\text { Enhancing contract } \\
\text { compliance }\end{array}$ & Realizing partnerships \\
\hline $\begin{array}{l}\text { Managing } \\
\text { external } \\
\text { and internal } \\
\text { contacts }\end{array}$ & $\begin{array}{l}\text { - Enhancing motivation } \\
\text { and internalization } \\
\text { - Realizing to compliance } \\
\text { standard operating } \\
\text { procedures } \\
\text { - Leadership Training on } \\
\text { the job }\end{array}$ & $\begin{array}{l}\text { - Enhancing and } \\
\text { maintaining service } \\
\text { orientation } \\
\text { - Rewarding target } \\
\text { compliance }\end{array}$ & $\begin{array}{l}\text { - Enhancing } \\
\text { professionalization } \\
\text {-Institutionalizing client } \\
\text { participation } \\
\text { - Enhancing coordinated } \\
\text { service delivery } \\
\text {-Account management }\end{array}$ \\
\hline
\end{tabular}

Sumber: Hill dan Hupe, (2002:190).

melalui pelaksanaan program pemberdayaan sosial dalam rehabilitasi rumah tidak layak huni sebagaimana amanat Peraturan Menteri Sosial Republik Indonesia Nomor 20 Tahun 2017 tentang Rehabilitasi Sosial Rumah Tidak Layak Huni dan Sarana Prasarana Lingkungan dan pengimplementasian kebijakan Peraturan Wali Kota Cilegon Nomor 30 Tahun 2016 tentang Petunjuk Pelaksanaan Rehabilitasi Sosial Rumah Tidak Layak Huni Kota Cilegon.

Untuk mendukung berjalannya program pemberdayaan sosial dalam rehabilitasi rumah tidak layak huni di Kota Cilegon bisa tercapai, maka peneliti berusaha memecahkan masalah di atas dengan menggunakan teori yang dikemukakan oleh Hill dan Hupe (2002), karena relevan dengan indikasi masalah yang telah dijelaskan oleh peneliti. Hill dan Hupe (2002) yang mengatakan bahwa ada tiga aspek dalam mengelola implementasi kebijakan, yaitu managing policy processes, managing inter organizational relations, dan managing external and internal contact. Berikut merupakan tabel perspektif keberhasilan dalam mengelola implementasi dari Hill dan Hupe (Tabel 3)

Tabel 2 Jumlah Seluruh Rumah dan JumlahRumah Tidak Layak Huni Kota Cilegon Tahun 2020

\begin{tabular}{|c|l|c|c|c|}
\hline \multirow{2}{*}{ No } & & \multicolumn{3}{|c|}{ Unit Rumah } \\
\cline { 3 - 5 } & Kecamatan & $\begin{array}{c}\text { Jumlah } \\
\text { Seluruh } \\
\text { Rumah }\end{array}$ & $\begin{array}{c}\text { Tidak } \\
\text { Layak } \\
\text { Huni }\end{array}$ & $\begin{array}{c}\% \\
\text { (Persentase) } \\
\text { Rumah } \\
\text { Tidak } \\
\text { Layah Huni }\end{array}$ \\
\hline 1 & Cibeber & 12.062 & 1.755 & $14.55 \%$ \\
\hline 2 & Cilegon & 9.902 & 1.386 & $14.00 \%$ \\
\hline 3 & Pulomerak & 10.277 & 1.816 & $17.67 \%$ \\
\hline 4 & Ciwandan & 10.472 & 236 & $22.59 \%$ \\
\hline 5 & Jombang & 14.233 & 1.586 & $11.14 \%$ \\
\hline 6 & Grogol & 9.114 & 1.177 & $12.91 \%$ \\
\hline 7 & Purwakarta & 8.976 & 1.225 & $13.65 \%$ \\
\hline 8 & Citangkil & 16.534 & 2.571 & $15.55 \%$ \\
\hline \multicolumn{2}{|c|}{ Total } & 91.570 & 13.882 & $15.16 \%$ \\
\hline
\end{tabular}

Sumber: Dinas Perumahan dan Permukiman Kota Cilegon, 2021. 
Jurnal Kebijakan Pembangunan Daerah, Vol.5, No.2, Desember 2021, Hal. 138 - 150

p-ISSN: 2597-4971, e-ISSN: 2685-0079

\section{Managing Policy Processes}

Membuat tanggungjawab yang jelas dapat membantu dalam proses pelaksanaan kebijakan. Pengelolaan proses kebijakan (managing policy processes) pada implementasi program pemberdayaan sosial dalam rehabilitasi rumah tidak layak huni di Kota Cilegon belum sepenuhnya berjalan dengan baik dikarenakan masih adanya rumah tidak layak huni yang belum selesai direhabilitasi sebagaimana data tabel 4.

Tabel 1.4 Rehabilitasi Rumah Tidak Layak Huni Kota Cilegon Tahun 2020

\begin{tabular}{|c|l|c|c|c|}
\hline \multirow{2}{*}{ No } & Kecamatan & $\begin{array}{c}|c| \\
\text { Tidak } \\
\text { Layak } \\
\text { Huni }\end{array}$ & $\begin{array}{c}\text { Selesai } \\
\text { Rehabilitasi }\end{array}$ & $\begin{array}{c}\% \\
\text { (Persentase) } \\
\text { Rumah } \\
\text { Tidak Layah } \\
\text { Huni }\end{array}$ \\
\hline 1 & Cibeber & 1.755 & 15 & $0.85 \%$ \\
\hline 2 & Cilegon & 1.386 & 9 & $0.64 \%$ \\
\hline 3 & Pulomerak & 1.816 & 15 & $0.82 \%$ \\
\hline 4 & Ciwandan & 236 & 4 & $1.69 \%$ \\
\hline 5 & Jombang & 1.586 & 0 & $0.00 \%$ \\
\hline 6 & Grogol & 1.177 & 0 & $0.00 \%$ \\
\hline 7 & Purwakarta & 1.225 & 2 & $0.16 \%$ \\
\hline 8 & Citangkil & 2.571 & 29 & $1.12 \%$ \\
\hline & Total & 13.882 & 74 & $0.53 \%$ \\
\hline
\end{tabular}

Sumber: Dinas Perumahan dan Permukiman, Dinas Sosial Kota Cilegon, 2021.

Berdasarkan hasil penelitian dan pengamatan di lapangan, rumah yang direhabilitasi yaitu rumah yang sudah memenuhi kriteria dan syarat untuk di rehabilitasi oleh Dinas Sosial Kota Cilegon. Pada tahap administrasi di dinas, proposal yang masuk dalam e-Bansos tidak lolos dalam verifikasi tahap selanjutnya karena adanya komponen yang kurang dalam proposal tersebut misalnya adanya ketidaklengkapan administrasi kepemilikan tanah. Sehingga, langkah-langkah antisipasif dalam rangka mengatasi permasalahan atau hambatan yang dihadapi yaitu dengan pendampingan dalam pembuatan proposal dan pendampingan dalam pertanggung jawaban dana bantuan.

Di sejumlah daerah baik kabupaten atau kota implementasi kebijakan tentang rehabilitasi rumah tidak layak huni yaitu dari indikator pembiayaan rehabilitas rumah tidak layak huni dengan mekanisme pengajuan serta pencarian bantuan program perbaikan rumah tidak layak huni dalam peraturan kepala daerah. Prosedur rehabilitas rumah tidak layak huni program perbaikan rumah pada peningkatan fisik seperti ketahanan rumah, akses air bersih dan lain-lain.

Pelaksanaan rehabilitas rumah tidak layak huni yang pelaksanaan rencana pemberian bantuan rumah tidak layak huni bagi masyarakat miskin, melakukan verifikasi pengajuan proposal permohonan bantuan pembangunan/ perbaikan rumah tidak layak huni, melaksanakan sosialisasi, monitoring dan evaluasi pelaksanaan pembangunan/perbaikan rumah tidak layak huni dan melaporkan pelaksanaan kegiatan bantuan pembangunan atau perbaikan rumah tidak layak huni kepada kepala daerah. (Ika dkk, 2018).

Belum optimalnya pengelolaan proses kebijakan salah satunya yaitu penugasan dan 
Jurnal Kebijakan Pembangunan Daerah, Vol.5, No.2, Desember 2021, Hal. 138 - 150 p-ISSN: 2597-4971, e-ISSN: 2685-0079

tanggung jawab yang jelas dalam penanggulangan RTLH di Kota Cilegon sebagaimana permasalahan yang peneliti angkat di atas. Disatu sisi merupakan kegiatan pemerintah dibidang urusan sosial yang dinanungi oleh Dinas Sosial dan disisi yang lain merupakan urusan perumahan yang dinaungi oleh Dinas Perumahan Rakyat dan Permukiman sebagai bentuk penaataan perumahan kota. Selama ini RTLH di Kota Cilegon hanya berada di lini sektor Dinas Sosial Kota Cilegon saja seperti yang termuat pada Peraturan Wali Kota Cilegon Nomor 30 Tahun 2016 tentang Petunjuk Pelaksanaan Rehabilitasi Sosial Rumah Tidak Layak Huni Kota Cilegon, sehingga upaya kedepan yaitu membuat kebijakan atau peraturan baru mengenai perangkat daerah mana saja yang dapat bersinergi dalam upaya percepatan perbaikan RTLH di Kota Cilegon.

Hal yang sama, faktor penghambat RTLH tersebut kurang meratanya pembagian anggaran di tiap-tiap kelurahan, anggaran yang dikeluarkan semakin berkurang, sumberdaya manusia pada pelaksanaan rehabilitasi rumah tidak layak huni dan pemerintah tidak ada penjelasan. Faktor pendukungnya dari dana pusat dan daerah bisa cepat diturunkan, rehabilitasi rumah tidak layak huni terus berkelanjutan kepada masyarakat yang layak membutuhkan dan pelaksanaan rehabilitas tepat sasaran. (Amelia dkk, 2018).

\section{Managing Inter-Organizational Relations}

Pengelolaan hubungan antar organisasi dalam pelaksanaan suatu kebijakan perlu didukung dengan adanya kejelasan tugas dan sumber daya yang cukup. Sumber daya sebagai pendukung atau pendorong dalam pelaksanaan program rehabilitasi rumah tidak layak huni, baik Sumber Daya Manusia (SDM) maupun sumber daya sarana dan parasarana masih kurang atau tidak sesuai dengan kebutuhan.

Tabel 1.5 Jumlah Sumber Daya Manusia Dinas Sosial Kota Cilegon Yang Menangani Program Pemberdayaan Sosial Dalam Rehabilitasi Rumah Tidak Layak Huni

\begin{tabular}{|c|c|c|c|c|c|c|c|}
\hline \multirow{2}{*}{ NO. } & \multirow{2}{*}{ JABATAN } & \multicolumn{4}{|c|}{ KUALIFIKASI PENDIDIKAN } & \multirow{2}{*}{ PNS } & \multirow{2}{*}{ NON PNS } \\
\hline & & SMA & $\mathrm{S} 1$ & $\mathrm{~S} 2$ & S3 & & \\
\hline 1. & Kepala Dinas Sosial & & & 1 & & 1 & \\
\hline 2. & Sekretaris Dinas Sosial & & & 1 & & 1 & \\
\hline 3. & $\begin{array}{l}\text { Kepala Bidang Pemberdayaan } \\
\text { Sosial dan Penanganan Fakir } \\
\text { Miskin }\end{array}$ & & & 1 & & 1 & \\
\hline 4. & Kasi Penanganan Fakir Miskin & & 1 & & & 1 & \\
\hline 5. & Staff/ Fungsional Umum & 2 & 1 & & & 1 & 2 \\
\hline & TOTAL & 2 & 2 & 3 & 0 & 5 & 2 \\
\hline
\end{tabular}

Sumber: Dinas Sosial Kota Cilegon, 2021. 
Jurnal Kebijakan Pembangunan Daerah, Vol.5, No.2, Desember 2021, Hal. 138 - 150 p-ISSN: 2597-4971, e-ISSN: 2685-0079

Sehingga, optimalisasi pelaksanaan rehabilitasi RTHL di Kota Cilegon belum bisa secara cepat diselenggarakan dengan maksimal dan masih bertahap. Berikut merupakan tabel jumlah SDM yang menangani program rehabilitasi RTLH di Kota Cilegon (Tabel 5).

SDM yang ada secara teknis di lapangan bila dilihat dari tabel di atas hanya dikerjakan oleh Kasi Penanganan Fakir Miskin yang dibantu hanya tiga staff saja. Sedangkan yang lain dari mulai pimpinan kepala dinas, sekretaris dinas dan kepala bidang hanya secara administratif saja terkait pimpinan rapat, surat menyurat dan disposisi. Sehingga, SDM yang diperlukan masih sangat banyak misalnya kebutuhan SDM fungsional seperti analis fakir miskin, analis pembangunan sosial, analis penataan sosial, analis perumahan dan konstruksi yang utama yaitu SDM pendamping masyarakat baik di setiap kelurahan maupun kecamatan.

Pengelolaan hubungan antar organisasi (managing interorganizational relations) pada implementasi program pemberdayaan sosial dalam rehabilitasi rumah tidak layak huni di Kota Cilegon belum bersinergi dengan baik antara perangkat daerah yang mengampu urusan rehabilitasi rumah tidak layak huni yaitu Dinas Sosial Kota Cilegon dengan perangkat daerah seperti Dinas Perumahan dan Kawasan Permukiman Kota Cilegon, kemudian dengan Cilegon Corporate Social Responsibility (CCSR) atau unsur elemen masyarakat lainnya. Hal tersebut diindikasikan karena belum berjalannya regulasi yang menegaskan mengenai tanggungjawab dan kewenangan serta penyusunan dan pembagian tugas atau tim dalam pelaksanaan rehabilitasi rumah tidak layak huni. Berikut tabel bantuan RTLH Kota Cilegon.

Kelemahan SDM terutama jumlah staf terbatas, dengan kejelasan informasi, wewenang dan pemanfaatan fasilitas dilakukan dengan baik menjadi masalah yang sering terjadi di instansi. (Hamdy dkk., 2019). Disposisi, yakni kecenderungan sikap penyelenggara program baik, acuh terhadap pelaksanaan tugas, fungsi dan wewenang. Struktur birokrasi baik, ditandai dengan ketaatan terhadap SOP dan penerimaan tugas, fungsi dan wewenang berdasarkan program kerja.

Hambatan SDM dengan keterbatasan staf dan keterlambatan masyarakat dalam menyelesaikan program dapat diatasi dengan baik melalui koordinasi antar bagian. Tindak lanjut permasalahan berdasarkan pada hambatan-hambatan dari tingkat desa/kelurahan dalam pelaksanaan program RTLH.

Respon masyarakat penerima manfaat program RTLH baik, ditandai dengan dukungan capaian program dan 
Jurnal Kebijakan Pembangunan Daerah, Vol.5, No.2, Desember 2021, Hal. 138 - 150 p-ISSN: 2597-4971, e-ISSN: 2685-0079

penerimaan mereka terhadap persyaratan yang harus dipenuhi baik secara administrasi dan kriteria pemanfaatan bantuan (Tabel 6).

Tabel 6 Jumlah Bantuan RTLH Kota

Cilegon

\begin{tabular}{|c|c|c|c|c|c|}
\hline TAHUN & $\begin{array}{c}\text { DPW } \\
\text { KELURAHAN }\end{array}$ & BAZNAS & CCSR & $\begin{array}{c}\text { DINAS } \\
\text { SOSIAL }\end{array}$ & JUMLAH \\
\hline 2017 & - & - & - & 150 & 150 \\
\hline 2018 & 56 & 10 & 10 & 57 & 133 \\
\hline 2019 & 72 & 12 & 18 & - & 102 \\
\hline 2020 & 13 & 10 & - & 74 & 97 \\
\hline JUMLAH & 141 & 32 & 28 & 281 & 480 \\
\hline
\end{tabular}

Sumber: Dinas Sosial Kota Cilegon, 2021.

Dari tahun ke tahun pada dasarnya bantuan RTLH Kota Cilegon di atas selain dari dana APBD juga peran $C S R$ atau unsur elemen masyarakat lainnya yang sangat membantu dalam upaya rehabilitasi rumah tidak layak huni. Kota Cilegon merupakan kota berbasis industri tentunya banyak perusahaan-perusahaan atau elemen masyarakat lainnya yang bisa diajak untuk bekerja sama atau menyelaraskan programprogram yang berkaitan langsung dengan masyarakat khususnya rehabilitasi RTLH di Kota Cilegon.

Ada enam karakteristik primer yang menentukan implementasi program RTLH yaitu: ukuran dan tujuan kebijakan, sumber daya, implementor, karakterstik organisasi, lingkungan ekonomi, sosial, budaya dan politik, serta sikap. (Satia dkk, 2019). Dari keenam tersebut aspirasi masyarakat yang berkaitan dengan pelaksanaan program
RTLH akan dihimpun, disampaikan pada pimpinan di DPRD dan dibahas bersama Kepala Daerah, sehingga pelaksanaan program RTLH bisa berjalan dengan baik sesuai dengan aspirasi masyarakat. Kemnudian memperkuat kapasitas Kelompok Swadaya Masyarakat (KSM) agar strategi/pelaksanaan program perbaikan RTLH menjadi lebih baik.

\section{Managing Eksternal and Internal Contact}

Mengelola hubungan eksternal dan internal berarti menjaga SOP dan memastikannya untuk dipatuhi, meningkatkan motivasi dengan adanya reward, dan memberikan pelatihan pada pelaksana kebijakan agar kebijakan tersebut dapat dilaksanakan sesuai dengan apa yang telah direncanakan. Menyesuaikan SOP diperlukan untuk kelancaran dalam mengimplementasikan suatu kebijakan. SOP menjadi salah satu acuan untuk pihak terkait dalam pelaksanaan program, namun belum optimalnya pelaksanaan mekanisme atau penerapan SOP mengenai implementasi program pemberdayaan sosial dalam rehabilitasi rumah tidak layak huni di Kota Cilegon saat ini pelaksanaan program masih mengacu kepada Peraturan Wali Kota Cilegon Nomor 30 Tahun 2016 tentang Petunjuk Pelaksanaan Rehabilitasi Sosial Rumah Tidak Layak Huni Kota Cilegon. 
Jurnal Kebijakan Pembangunan Daerah, Vol.5, No.2, Desember 2021, Hal. 138 - 150 p-ISSN: 2597-4971, e-ISSN: 2685-0079

Di sisi yang lain minimnya pelatihanpelatihan, baik bimbingan teknis ataupun reward kepada aparatur, sehingga motivasi pegawai masih seperti itu-itu saja. Tentunya hal tersebut harus menjadi bahan evaluasi pemerintah daerah khususnya dibidang perencanaan, penataan dan pengawasan pembangunan. Untuk itu, dalam penanganan RTLH (Cintamy dkk, 2020), perlu untuk menjalin komunikasi, baik dalam bentuk sosialisasi maupun pemantauan dan pengawasan, harus merekrut tenaga pendamping sosial, harus konsisten dan komitmen, harus dilengkapi dengan Standar Operasional Prosedur (SOP) dan perlu mengalokasikan anggaran yang lebih.

Dengan demikian, ketiga aspek yang dijelaskan tersebut dinilai mampu menjelaskan Implementasi Program Pemberdayaan Sosial Dalam Rehabilitasi Rumah Tidak Layak Huni di Kota Cilegon. Aspek-aspek tersebut relevan dengan penelitian yang dilakukan oleh penulis karena sesuai dengan indikasi-indikasi masalah yang telah ditemukan.

Selain itu identifikasi masalah dalam penelitian ini dapat dianalisis dengan menggunakan ketiga aspek tersebut. Manajemen program pun tetap untuk diperhatikan karena mengarah kepada efektivitas pelaksanaan program RTLH. (Febrianza dkk, 2020). Perencanaan (Planning), terbatasnya besaran anggaran yang dimiliki pemerintah jika dibandingkan dengan jumlah masyarakat masyarakat yang diusulkan sebagai penerima bantuan, yang tidak sebanding dengan jumlah masyarakat sasaran yang ada, sehingga terjadi bias dalam pengajuan usulan dan verifikasi.

Koordinasi masih terkendala waktu sehingga dilakukan upaya persuasif baik di jam kerja maupun di luar jam kerja. Penggerakkan (Actuating), sosialisasi yang dilakukan tidak maksimal, masyarakat cukup antusias berpartisipasi. Namun, pembangunan yang dilaksanakan cukup lambat dikarenakan kurangnya keahlian maupun dikarenakan kesibukan masyarakat mencari nafkah.

Untuk mengatasi hal tersebut perlunya upaya memotivasi masyarakat untuk dapat melaksanakan pembangunan rumahnya termasuk memberi upah. Pengawasan (Controlling), pengawasan eksternal dalam Pelaksanaan Program Rehabilitasi Rumah Tidak Layak Huni di Kota Palembang masih sulit dilakukan mengingat luasnya wilayah pengawasan/ banyaknya masyarakat penerima bantuan program RTLH, sehingga seringkali penerima bantuan rehabilitasi rumah tidak layak huni dirasakan masih belum merata. 
Jurnal Kebijakan Pembangunan Daerah, Vol.5, No.2, Desember 2021, Hal. 138 - 150

p-ISSN: 2597-4971, e-ISSN: 2685-0079

KESIMPULAN DAN REKOMENDASI

\section{Kesimpulan}

Berdasarkan hasil penelitian dan pembahasan mengenai implementasi program pemberdayaan sosial dalam rehabilitasi rumah tidak layak huni di Kota Cilegon dapat diambil kesimpulan sebagai berikut:

1. Pengelolaan proses kebijakan menyiratkan tentang penugasan tanggungjawab yang jelas dalam memenuhi tugas, seperti kapan dan dimana kebijakan tersebut diterapkan. Pada saat yang sama, proses pengelolaan kebijakan membutuhkan perhatian yang memadai di dalam perumusan kebijakan dan keputusan membuat undang-undang dan program kebijakan, dengan tugas dan tanggung jawab yang jelas.

2. Pengelolaan hubungan antar organisasi, dengan adanya kejelasan pembagian tugas dan ruang lingkup kompetensi sangatlah penting. Pembagian tugas yang jelas dapat membantu dalam proses implementasi dari kebijakan agar dapat mencapai tujuan. Kepatuhan dalam kontrak merupakan kegiatan dalam proses pengelolaan hubungan antar organisasi. Hal tersebut merupakan tujuan dalam menciptakan terwujudnya kerjasama antar organisasi atau kemitraan.
3. Pengelolaan hubungan atau interaksi ekternal dan internal dimaksudkan untuk mengelola standar operasional prosedur dan memastikannya untuk dipatuhi, menunjukkan kepemimpinan, meningkatkan motivasi dan internalisasi, juga memberikan pelatihan pada pelaksana. Pada tingkat ini, pengelolaan interaksi yaitu semua hal mengenai proses meningkatkan dan mempertahankan orientasi pelayanan.

\section{Rekomendasi}

Berdasarkan pada kesimpulan di atas, maka peneliti mengajukan beberapa rekomendasi yaitu:

1. Harus adanya kejelasan pembagian tugas dalam pelaksanaan program rehabilitasi rumah tidak layak huni. Sehingga perlu diperjelas dan diperinci agar pihak pelaksana memiliki peran yang jelas dalam pelaksanaannya. Hal ini dikarenakan dengan adanya pembagian tugas yang jelas dapat meminimalisir kesalahan dalam pelaksanaan rehabilitasi rumah tidak layak huni.

2. Sumber daya sebagai pendukung atau pendorong dalam pelaksanaan program rehabilitasi rumah tidak layak huni seperti sumber daya manusia tenaga yang ada harus ditambah dengan mengrekrut kembali aparatur yang berkompeten di bidang tersebut supaya sebanding dengan 
Jurnal Kebijakan Pembangunan Daerah, Vol.5, No.2, Desember 2021, Hal. 138 - 150 p-ISSN: 2597-4971, e-ISSN: 2685-0079

wilayah yang harus ditangani. Kemudian sumber daya sarana dan parasarana harus sesuai dengan kebutuhan.

3. Harus adanya kejelasan mekanisme regulasi dan SOP yang khusus mengatur implementasi program rehabilitasi rumah tidak layak huni Kota Cilegon. Hal ini tentu sangat berpengaruh pada maksimalnya pelaksanaan program rehabilitasi rumah tidak layak huni di Kota Cilegon, sehingga pihak-pihak terkait yang mengelola program dapat menjalankan tugas dan fungsinya dengan baik. Kemudian jajaran aparatur agar diikutsertakan pelatihan-pelatihan atau bimbingan teknis bila perlu sebagai bentuk motivasi pegawai sesering mungkin diberikan reward agar kinerjanya meningkat.

\section{DAFTAR PUSTAKA}

Hamdy, A., Badaruddin, \& Humaizi. (2021). Implementasi Program Rumah Tidak Layak Huni di Kabupaten Asahan Pada Tahun 2019. Perspektif, 10(1): 280292,

Hasan, E.. (2011). Filsafat Ilmu dan Metodologi Penelitian Ilmu Pemerintahan. Bogor: Ghalia Indonesia.

Herdiansyah, H. (2012). Metodologi Penelitian Kualitatif Untuk Ilmu-Ilmu Sosial. Jakarta: Salemba Humanikae

Hill, M. \& P. Hupe. (2002). Implementing Public Policy: Governance in Theory and in Practice. London: SAGE Publication.
Amelia, I. S., Teguh, C. T. Prakoso, \& Hariati. (2018). Implementasi Kebijakan Tentang Rehabilitas Rumah Tidak Layak Huni Di Desa Perjiwa Kecamatan Tenggarong Seberang Kutai Kartanegara. eJournal Administrasi Negara, (6)4: 8299-8313.

Jones, C.O. (1994). Pengantar Kebijakan Publik (Public Policy). Jakarta: PT. Grafindo Persada.

Febrianza, M., \& Sutinah. (2020). Analisis Pelaksanaan Program Rehabilitasi Rumah Tidak Layak Huni Di Kota Palembang. Jurnal Administrasi Publik, 25(02):

Cintamy, M. E., W. Bogar, \& F. Mamonto. (2020). Implementasi Program Rehabilitasi Sosial Rumah Tidak Layak Huni (RS-RTLH) di Kota Tomohon. Jurnal Kajian Kebijakan dan Ilmu Administrasi Negara, 2(2): 32-39.

Muharam, R.S. \& B. Rusli. (2019). Implementasi Program Rumah Tidak Layak huni (Rutilahu) di Kabupaten Bandung. Konferensi Nasional Ilmu Adminstrasi STIA LAN Bandung: 1-7.

Subarsono, (2015). Analisis Kebijakan Publik. Yogyakarta: Pustaka Pelajar.

Tachjan, (2006). Implementasi Kebijakan Pubik. Bandung: AIPI. 